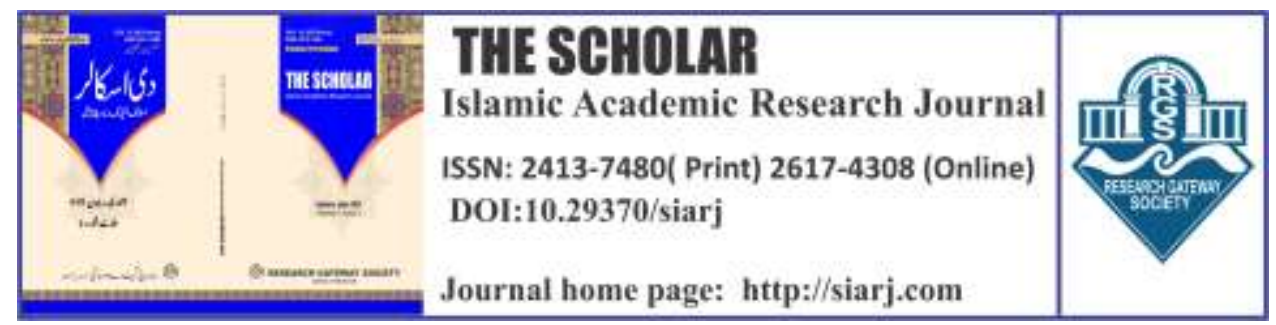

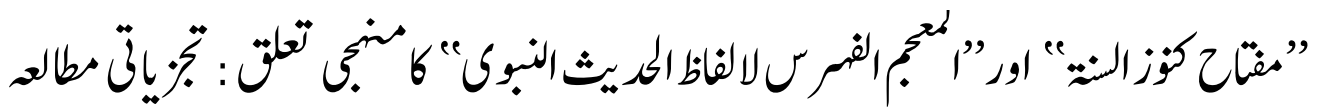

\title{
METHODOLOGICAL ASSOCIATION BETWEEN “MIFTAH KUNUZ-AL-SUNNAH” AND “AL-MUJAM AL-MUFAHRIS LI ALFAZ AL HADITH AL NABVI": ANALYTICAL STUDY
}

\section{Muhammad Samiullah}

Assistant Professor, Department of Islamic Thought and Civilization, University of Management and Technology, Lahore, Pakistan Email: muhammad.samiullah@umt.edu.pk

\section{ORCID ID: https://orcid.org/0000-0002-0998-0549}

To cite this article:

Samiullah, Muhammad. "Methodological Association between 'Miftah Kunuz-al-Sunnah' and 'Al-Mujam al-Mufahris Li Alfaz al Hadith al Nabvi': Analytical Study." The Scholar-Islamic Academic Research Journal 7, No. 2 (November 15, 2021).

To link to this article: https://doi.org/10.29370/siarj/issue13urduar1

Journal

Publisher

DOI:

URL:

License:

Journal homepage

Published online:
The Scholar Islamic Academic Research Journal Vol. 7, No. 2 || July-December 2021 || P. 1-17

Research Gateway Society

10.29370/siarj/issue13urduar1

https://doi.org/10.29370/siarj/ issue12urduar1

Copyright c 2017 NC-SA 4.0

www.siarj.com

2021-11-15 


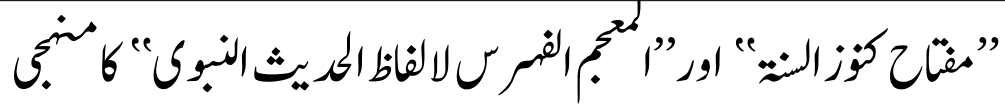

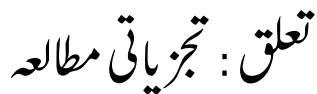 \\ METHODOLOGICAL ASSOCIATION BETWEEN “MIFTAH KUNUZ- AL-SUNNAH” AND “AL-MUJAM AL-MUFAHRIS LI ALFAZ AL HADITH AL NABVI": ANALYTICAL STUDY
}

\begin{abstract}
Muhammad Samiullah
ABSTRACT:

It is peculiarity of Quran and Hadith sciences that their system of editing and development had been carried out in such methodical manner that where the texts of the original sources of science were not only preserved but their interpretations and commentaries were also unspoiled. Likewise, predominantly in the Hadith sciences, the indexation system was designed in such a way that future generations could feel at ease. They rendered a system of Takhrij-o-Taliq of hadiths. Among these, Atraf al-Hadith is a reference system of Ahadith in which the author of the book mentions a well-known and sometimes unknown or alphabetical word or phrase that represents whole text of hadith, then the author indicates towards certain or specific books in which the hadith is mentioned. This indexation system of editing is also called Kitab al-Faharis. Dutch Philosopher Johan Herman Wensinck is renowned due to his Hadith Projects. This paper discusses and examine his two great Hadith projects Miftah Kunuz al-Sunnah and alMu'jam al-mufahras li-alfāẓ al-Hadīth al-Nabawī. A methodological analysis between these two works is presented and some of inaccuracies are pointed out to be reformed for the future publishing.
\end{abstract}

KEYWORDS: Atraf al-Hadith, Wensinck, Miftah Kunuz al-Sunnah, al-Mu'jam al-Mufahras 


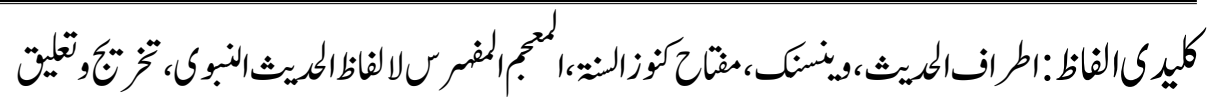
تقارف:

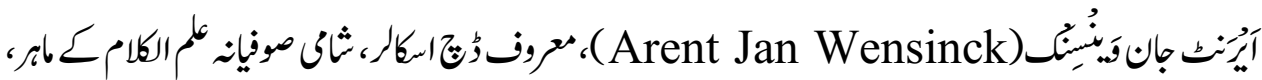

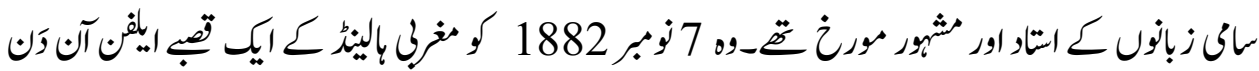

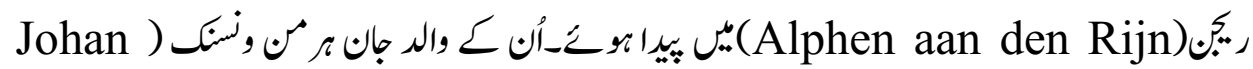

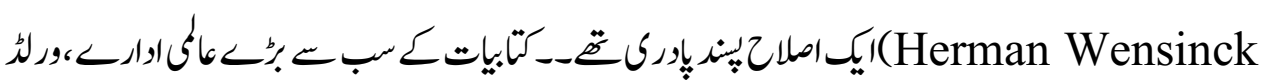

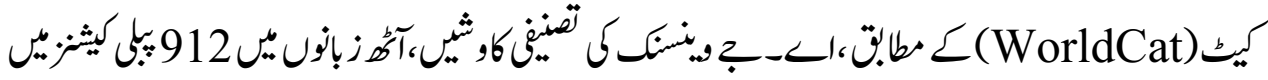

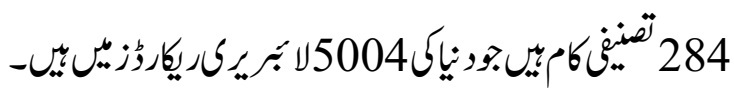

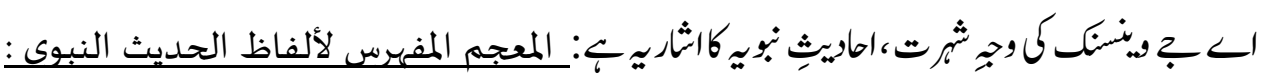

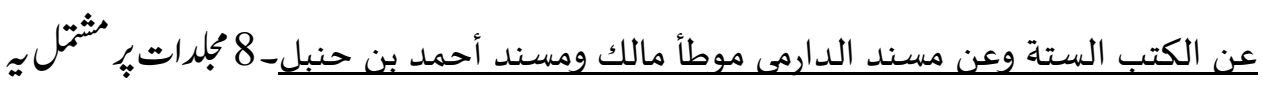

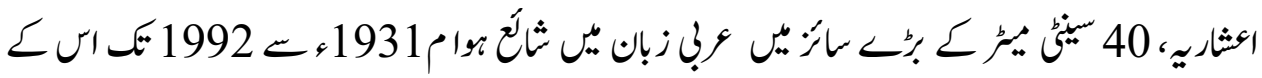

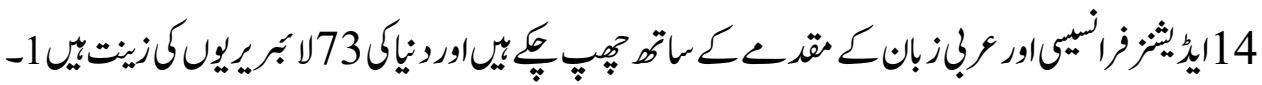

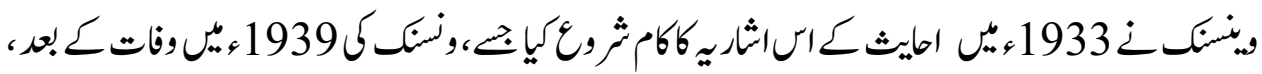

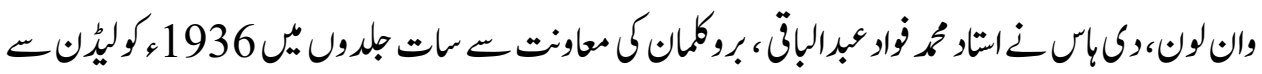

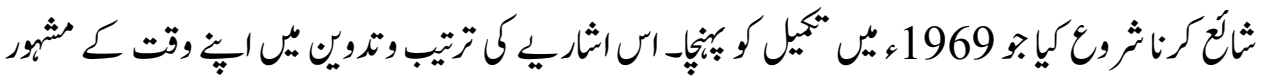

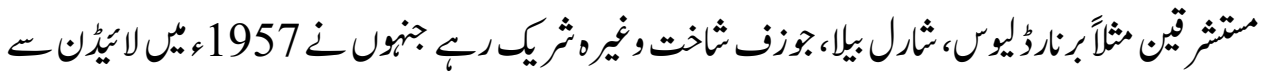

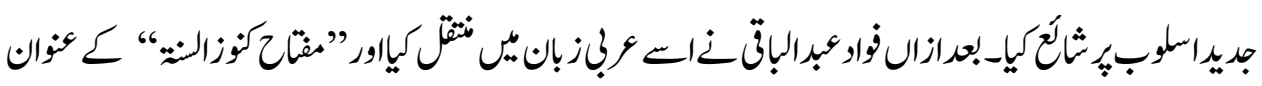

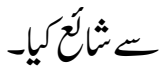

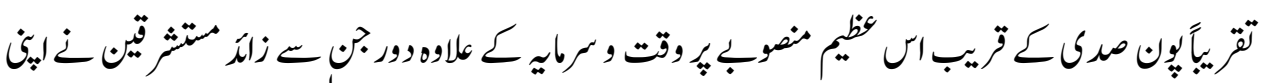

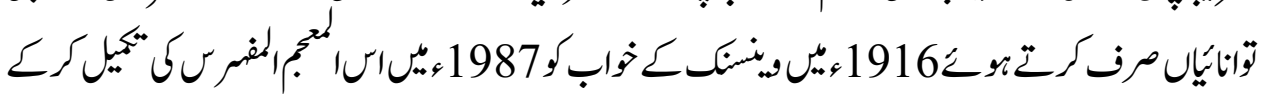

1. A. J. Wensinck. al-Mu'jam al-mufahras li-alfāẓ al-Ḥadīth al-Nabawī : 'an al-kutub al-sittah wa-'an Musnad al-Dārimī wa-Muwațța' Mālik waMusnad Aḥmad ibn Ḥanbal.( Līdin ; New York : Brīl, 1936-1988.) 


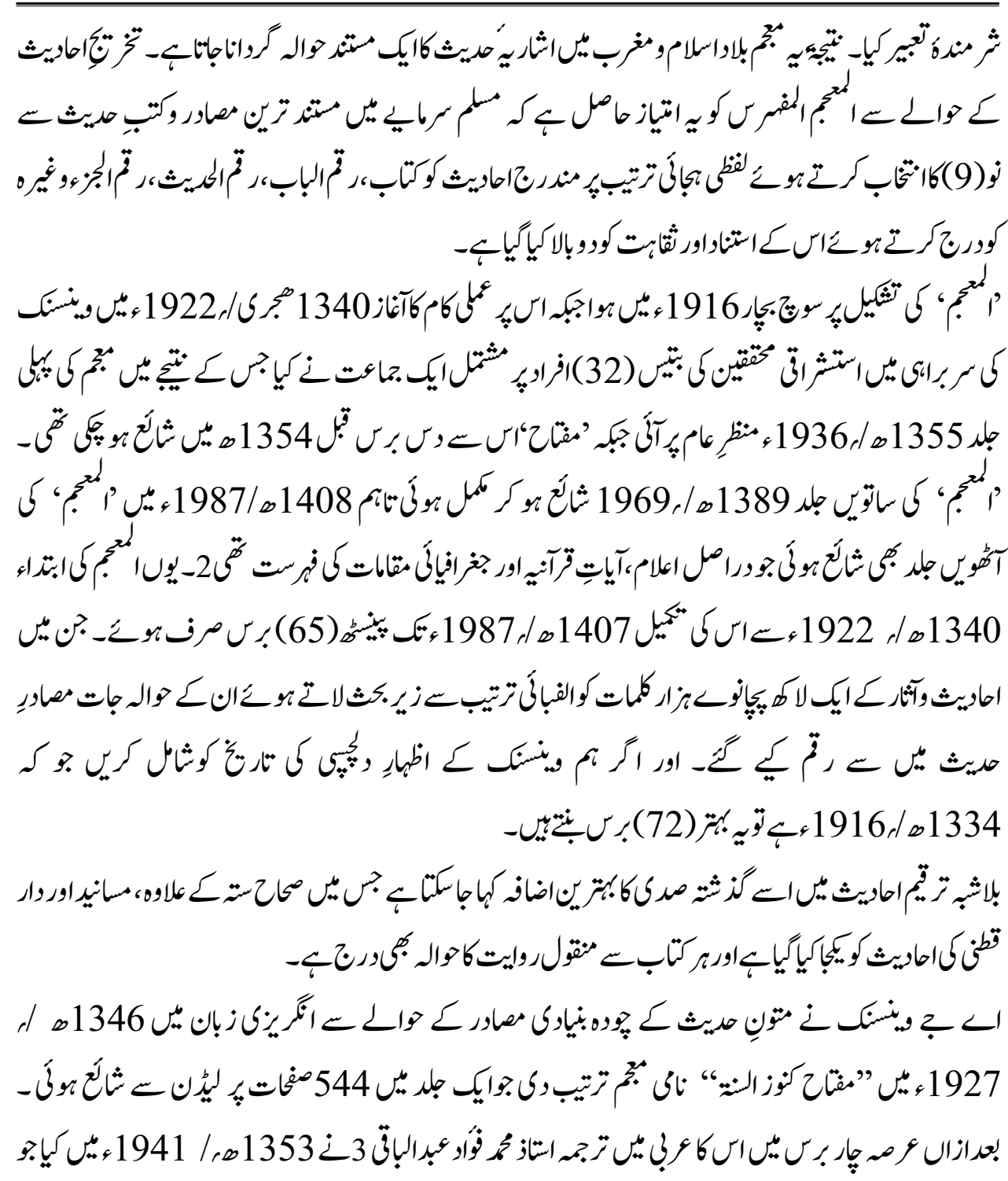

2. Hayyani, Muhammad Abdullah. Mimma Yulahiz ala kitabai Miftah Kunuz al Sunnah wal Mujama al Mufahris li alfaz al Hadith. Riyaz, 1433 AH. P. 9

3. Al-Zarkali, Khair ud Din. Al-Alam. Dar al Ilam lil Malayeen, Beirut. 1986 ; Nimat, Ahamad Faraz. Muhammad Fawwad Abdu I Baqi Sahib Faharis al Quran wal Hadith. Mujalla al Arabi, No. 118. 1968. p. 42 


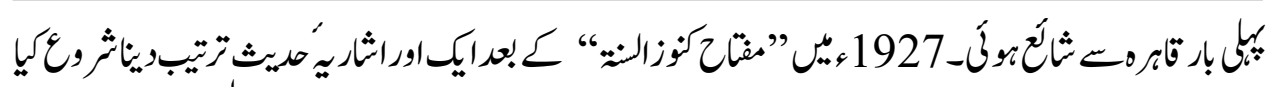

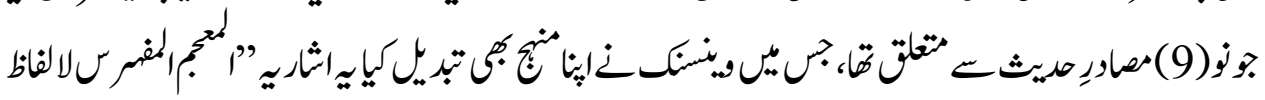

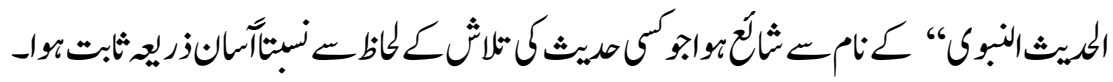

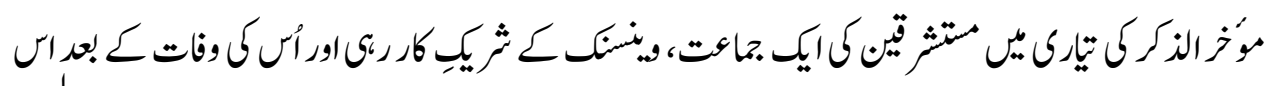

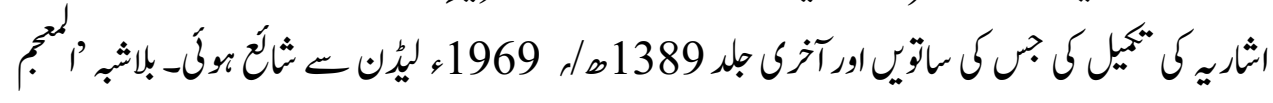

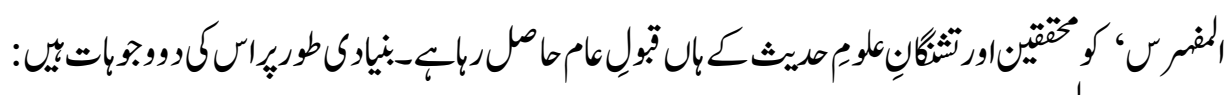

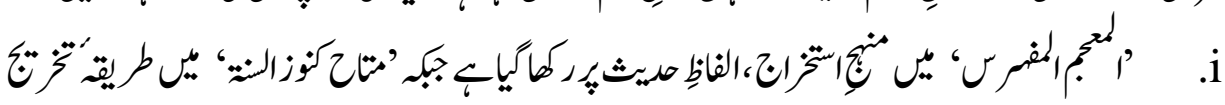

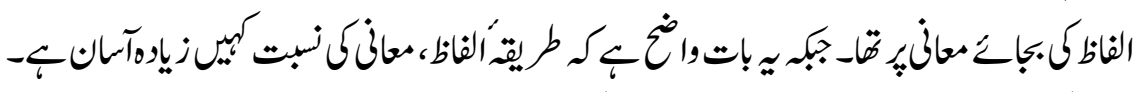

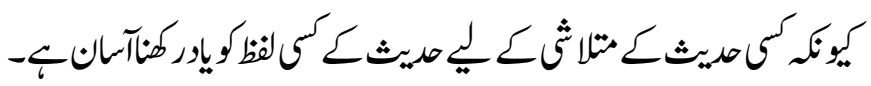

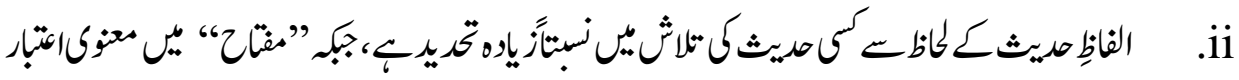

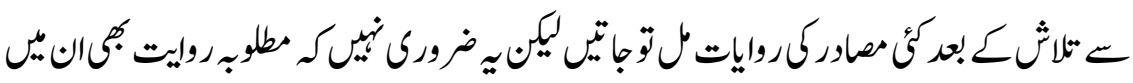

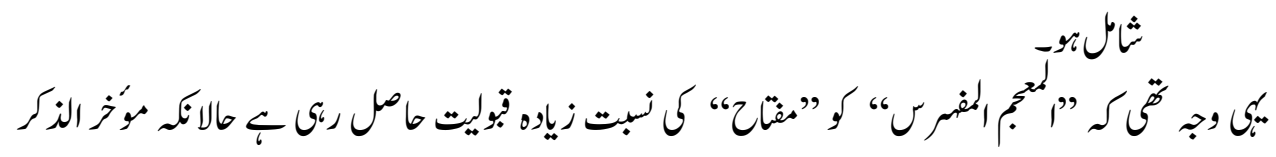

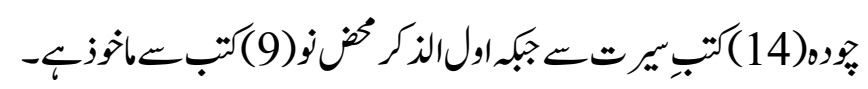

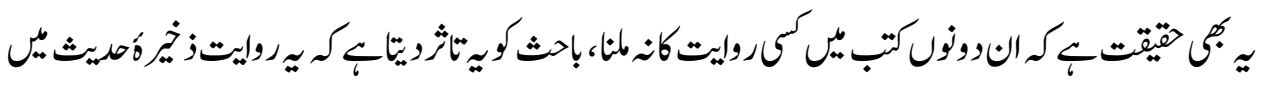

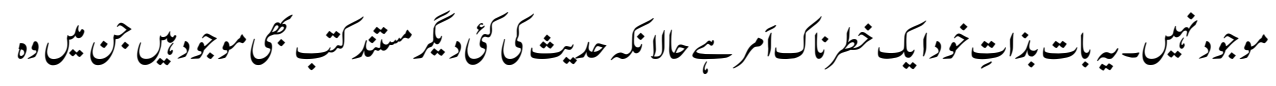

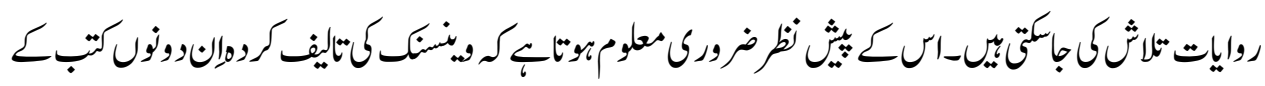

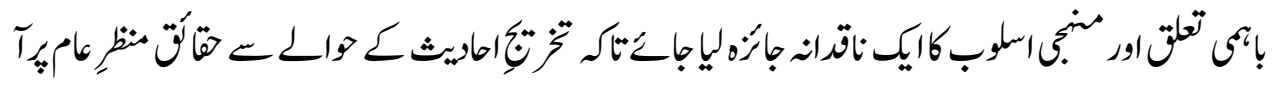

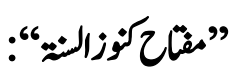

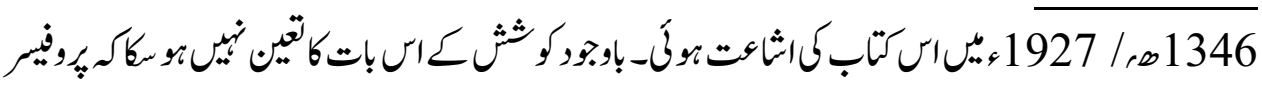

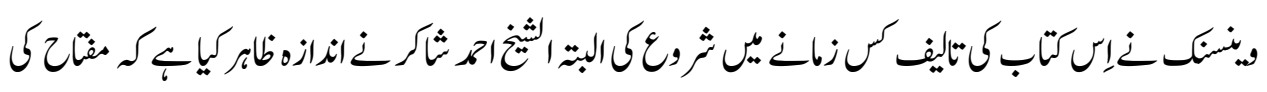




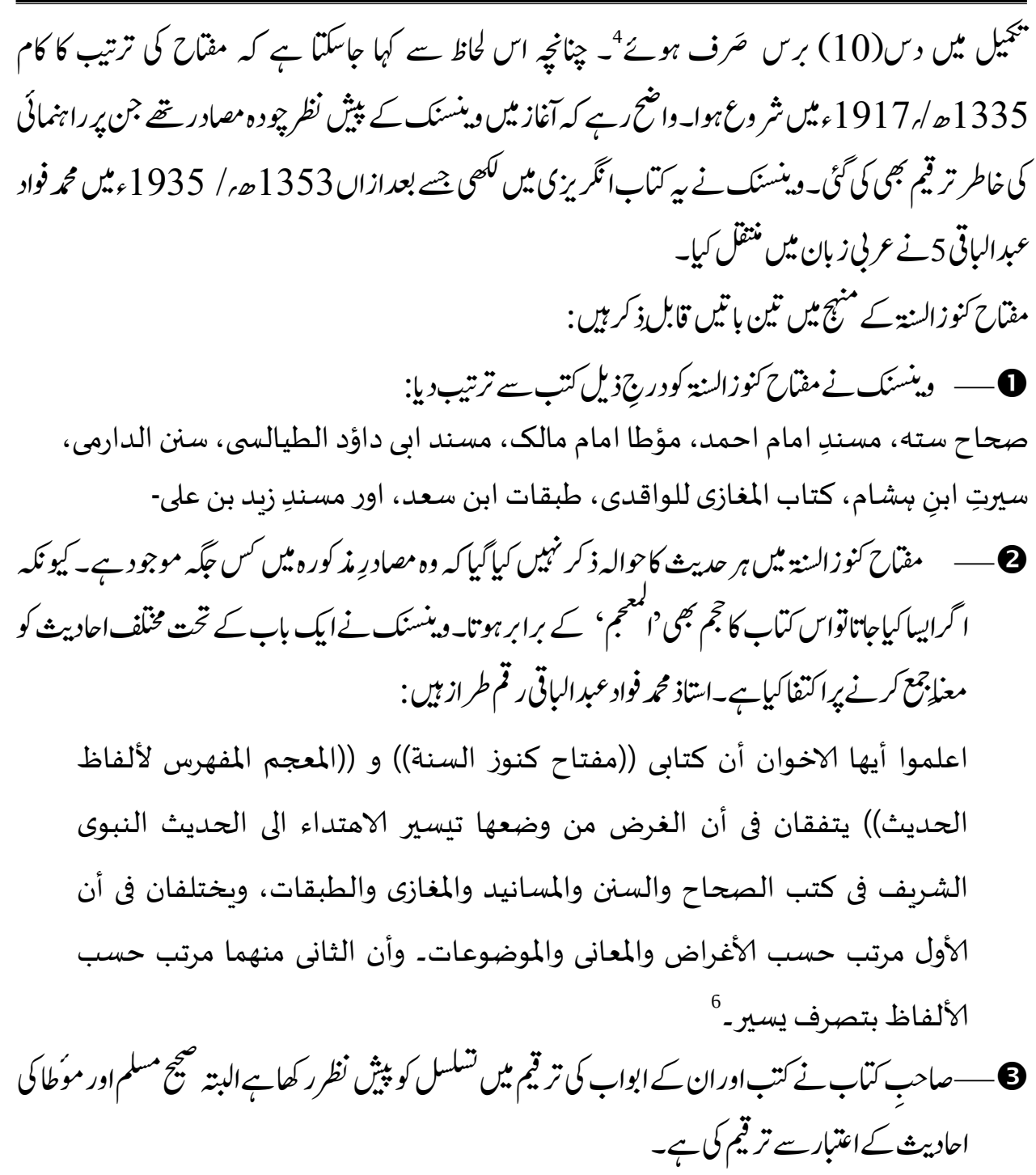

4. Ahmad Muhammad Shakir. Al-Tarif bi kitab Miftah Kunuz al Sunnah. Egypt. 1353 AH. p. c

5. Fawwad Abd al Baqi, Muhammad. Taiseer al Manfia bi kitabi Miftah Kunuz al Sunnah wal Mujam al Mufahris li alfaz al Hadith al Nabvi. Dar al Hadith Cairo. 1978. 484 pages

6. Arent Jan Wensinck. Miftah Kunuz al Sunnah. Tajuman al Sunna Lahore. $1398 \mathrm{AH}$, p. d 


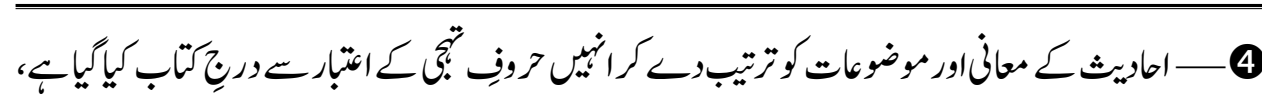

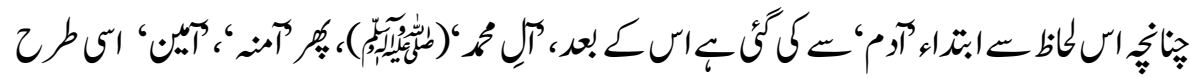

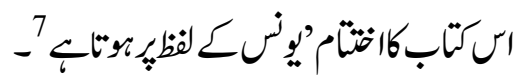

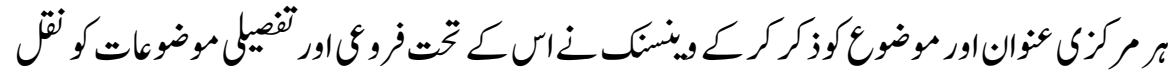

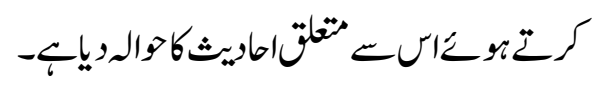

\begin{tabular}{|c|c|c|}
\hline نز كَنِطباوت & مطبوء & كتاب \\
\hline (ء1862_(1278) & ل ليُّن & العجلبخرى \\
\hline (1867_/285) & & \\
\hline (1907هـ1325) & & \\
\hline (1326هـ/_1908) & & \\
\hline 129هـ/1873، & بولاق & الصيحسلم \\
\hline 1312هـ/1894،1895 & القاره & السن للنساقُ" \\
\hline 1313هـ/1895. & القاره & السنثلابناج \\
\hline 1337هـ/1918ء & وبل & ستن الدارق" \\
\hline 1279هـ/21862ء & القايره & المؤطا \\
\hline 1321ــ & ميرآبار & منداطيالى \\
\hline 1919 & 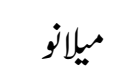 & مندزيربن على \\
\hline 1313هـ & القاره & كنراطاماتم \\
\hline
\end{tabular}

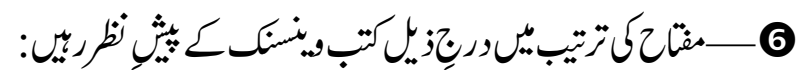

7. Al-Kabisi, Abdul Aziz Shakir Hamdan. Juhud al Mustashrqin al Holindiyeen fi fihersat mauzooat al Seera al Nabviya. Riaz. 2011. p. 9 
THE SCHOLAR (July-December 2021)

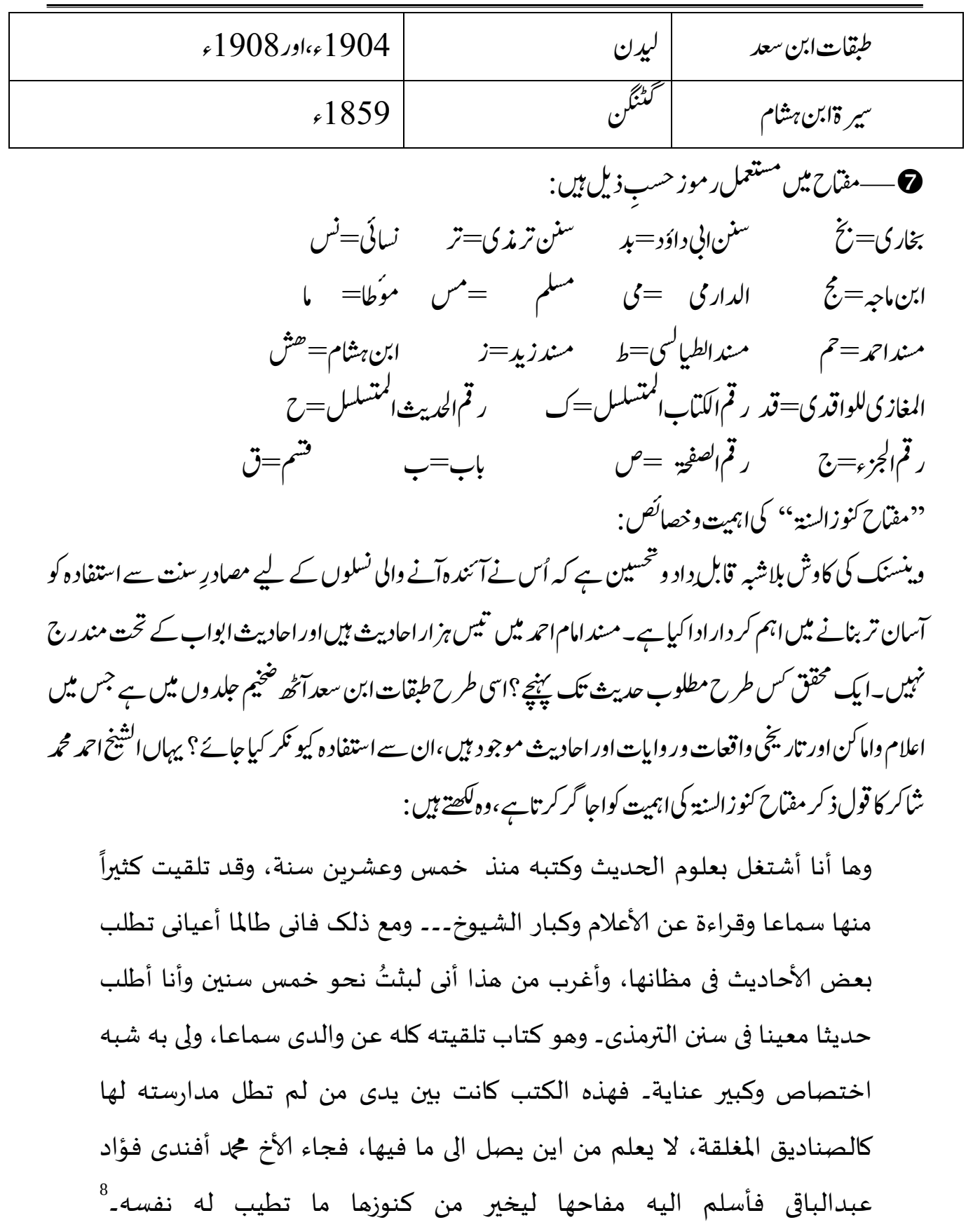

8. Ahmad Muhammad Shakir. p. 3 


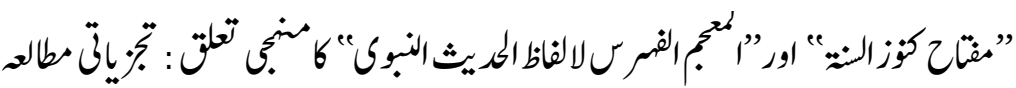

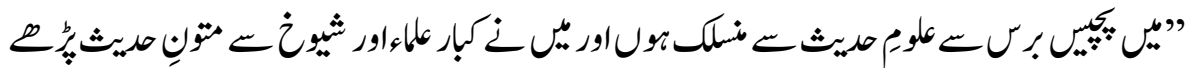

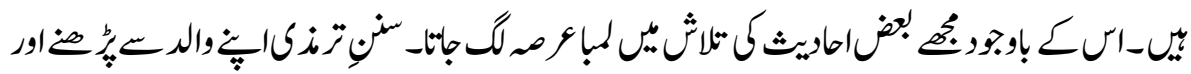

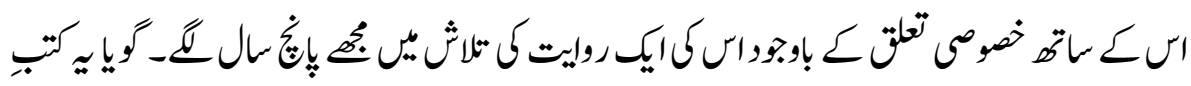

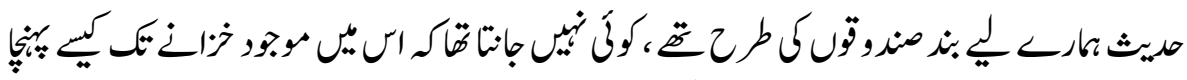

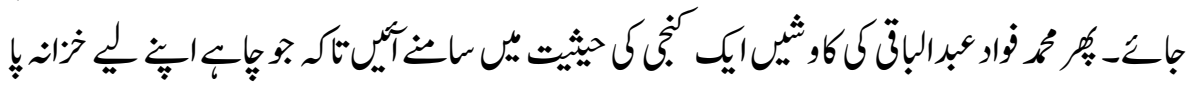
"E

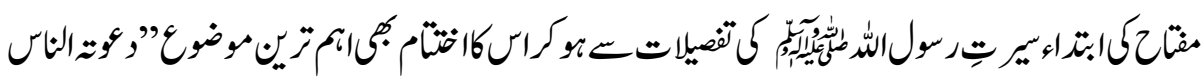

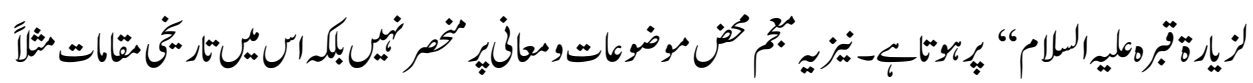

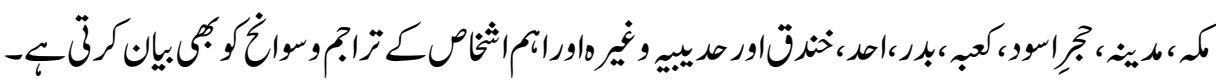

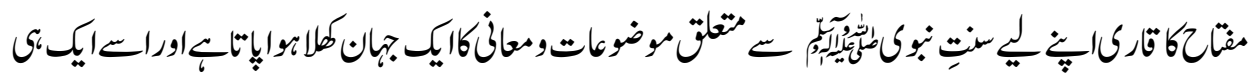

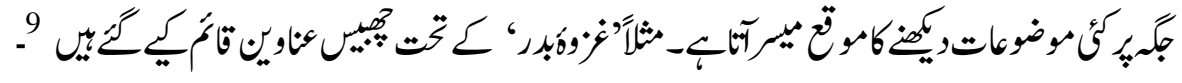

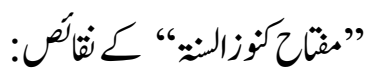

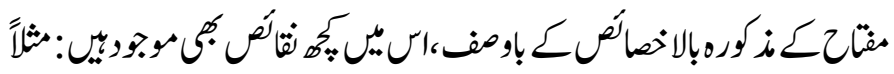

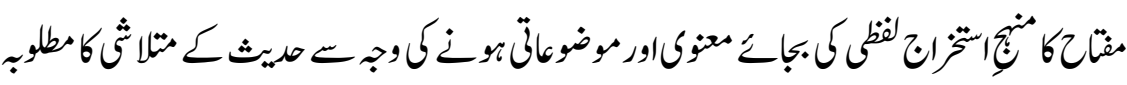

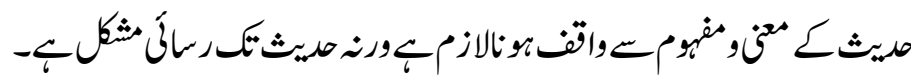

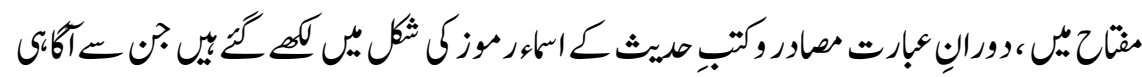

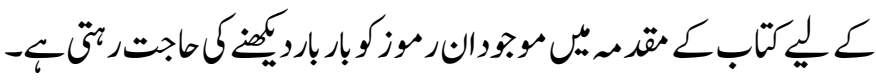

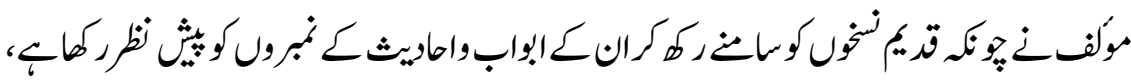

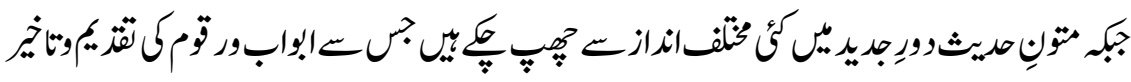

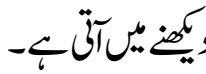

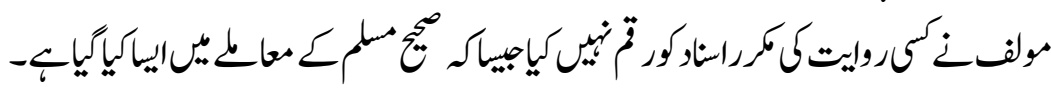

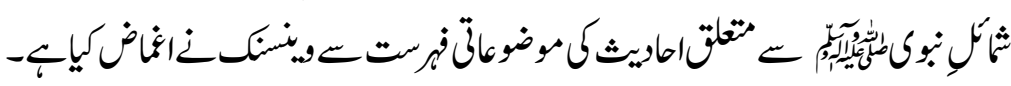

9. Al-Kabisi, Abdul Aziz Shakir Hamdan. p.12 


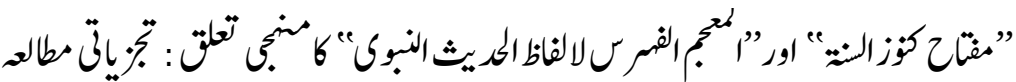

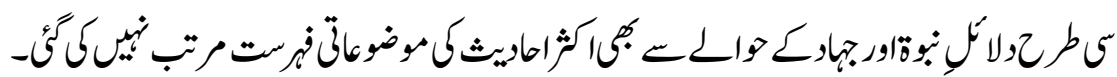

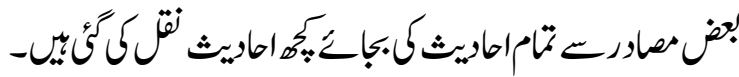

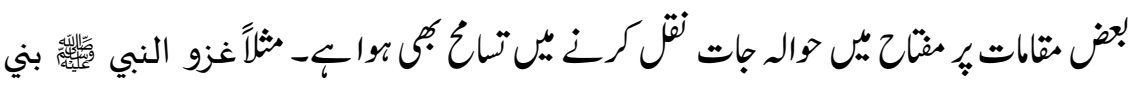

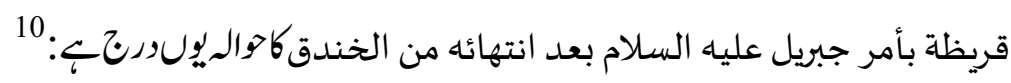

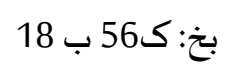$$
\text { مس:ك } 32 \text { ح } 65 \text { قابل ب69 }
$$

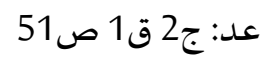

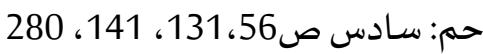

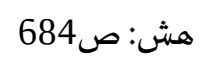

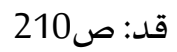

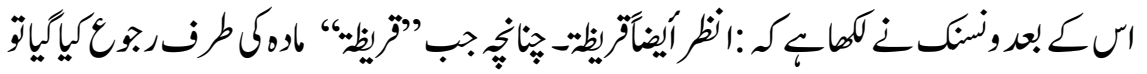

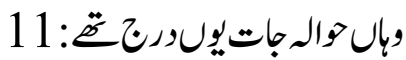

$$
\begin{aligned}
& \text { بخ: ك64 ب } 29 \\
& \text { عد: ج2 ق1 ص53و55 ج3ق2ص36و6 } \\
& \text { حم: سادس 141، } 280 \\
& \text { هش:ص48 }
\end{aligned}
$$

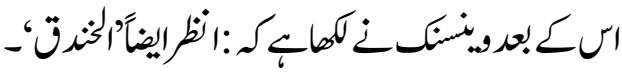

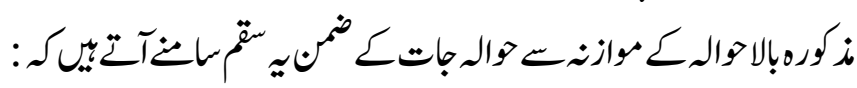

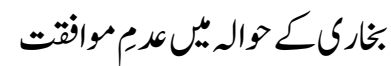

$$
\begin{aligned}
& \text { • }
\end{aligned}
$$

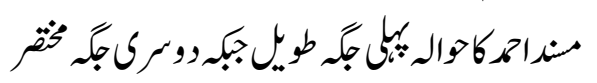

10. Arent Jan Wensinck Miftah Kunuz al Sunnah. p. 181

11. Ibid. p. 407 


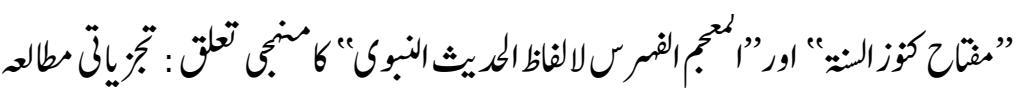

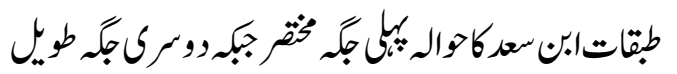

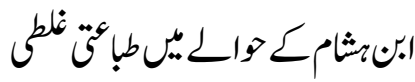

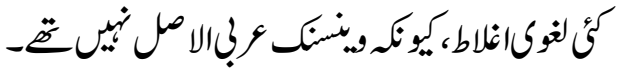

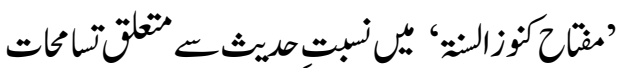

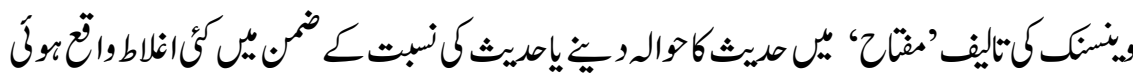

$$
\text { ب. }
$$

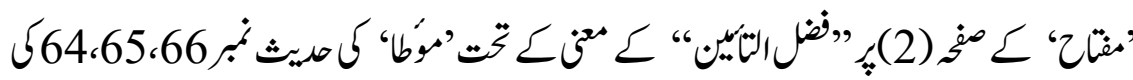

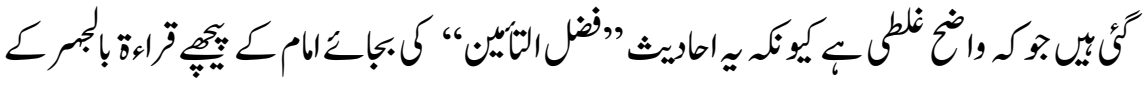

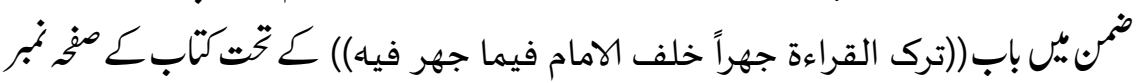

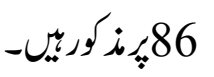

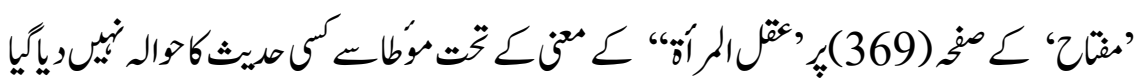

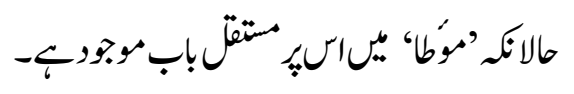

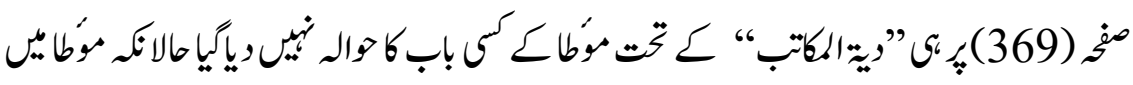

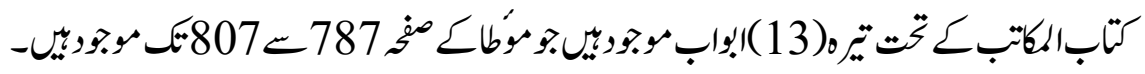

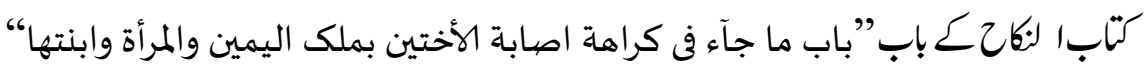

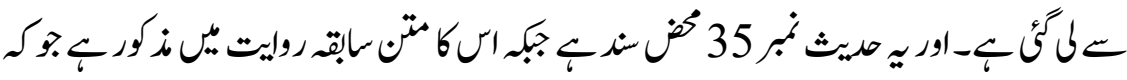

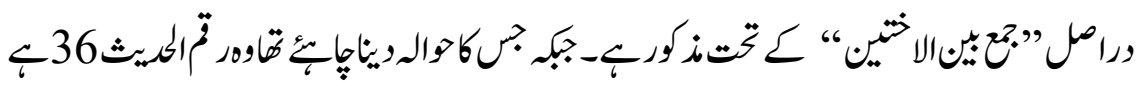

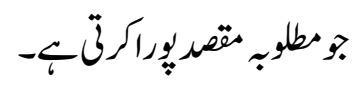

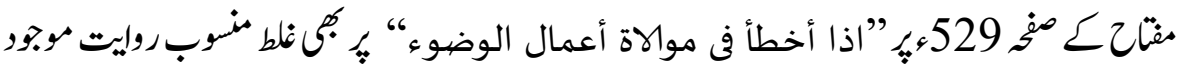

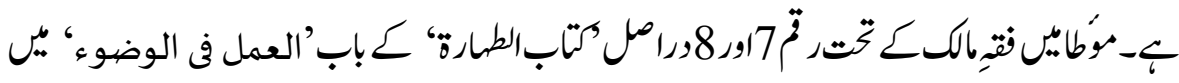

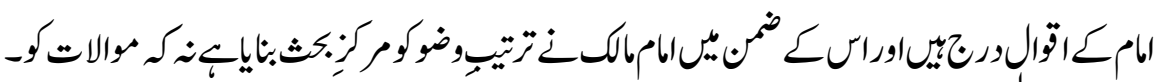

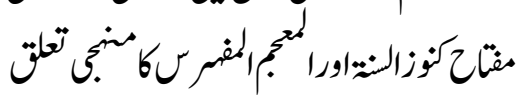

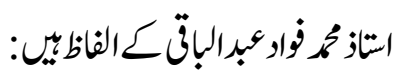
اعلموا أيها الاخوان أن كتابتى ((مفتاح)) و ((المعجم)) يتفقان في ان الغرض من 
وضعهما تيسير الاهتداء الى الحديث النبوى الشريف في كتب الصحاح والسنن والمغازى والطبقات، ويختلفان فى ان الاول منهما مرتب حسب الأغراض والمعانى

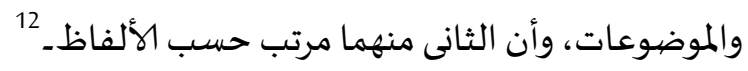

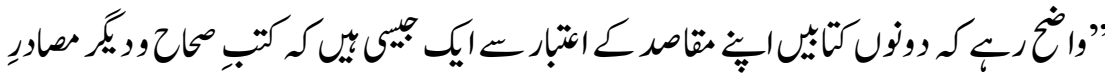

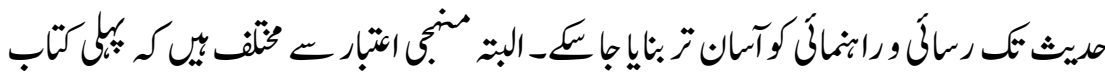

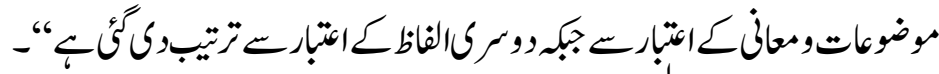

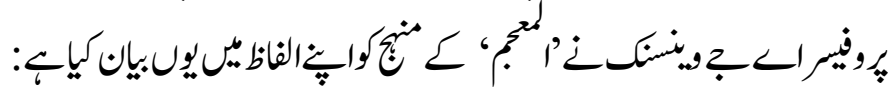

ان الكلمات المهمّة أياً كانت أهميتها هذه عوملت معاملة الكلمات الأصول، مصحوباً بالفقرات المأخوذة من النصوص، أما الكلمات التى تتكرر في كثرة بالغة، أو الكلمات التى ليست لها أهمية متميزة فقد سُجلت فقط دون مصاحبة هذه الفقرات، واذن فالكلمات المستبعدة هى فقط الكلمات التى لا تتميز بأى أهمية بالنسبة لهذا

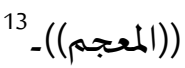

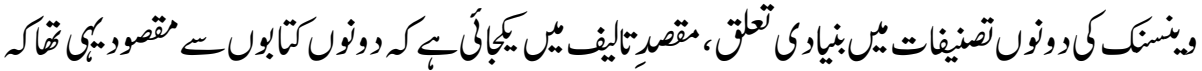

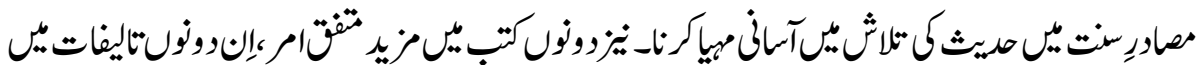

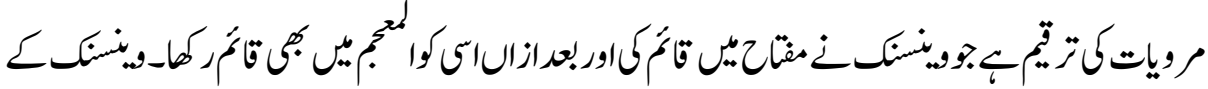

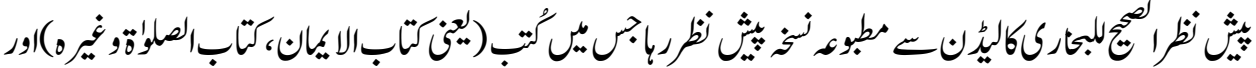

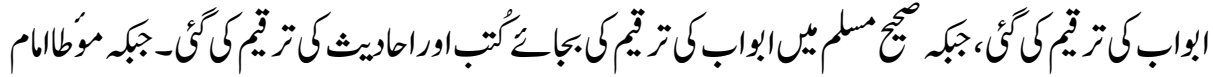

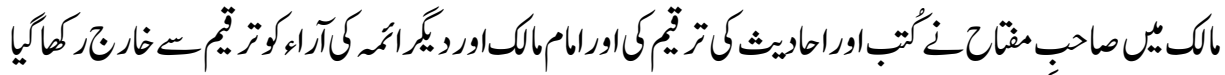

12. Ibid. preface

13. Arent Jan Wensinck. Al-Mujam al Mufahris li alfaz al Hadith al Nabvi. Lieden. 1967. Vol 1, p. 8 14. Hayyani, Muhammad Abdullah. Mimma Yulahiz ala kitabai Miftah Kunuz al Sunnah wal Mujama al Mufahris li alfaz al Hadith. Riyaz, 1433 AH. P. 127 


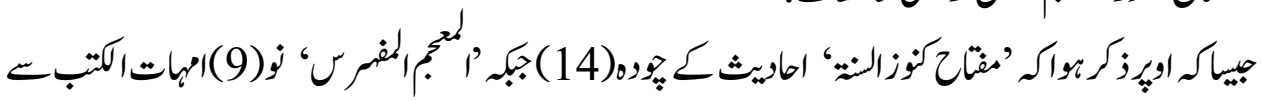

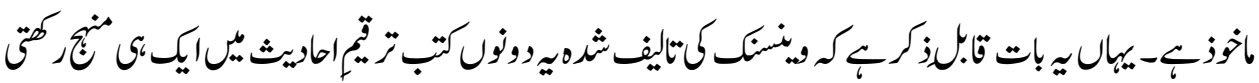

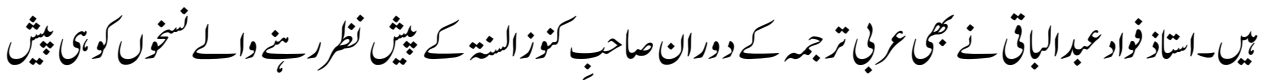

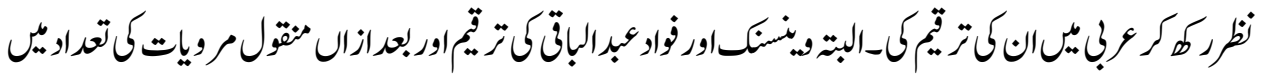

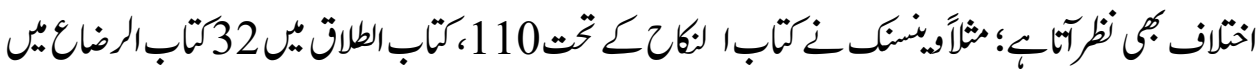

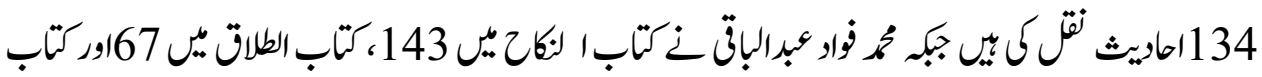

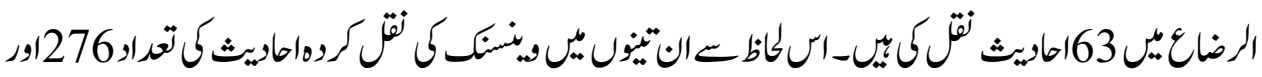

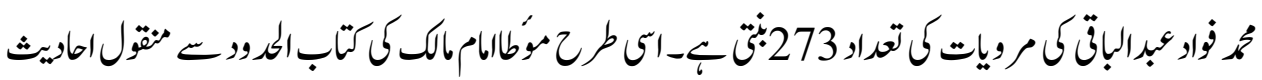

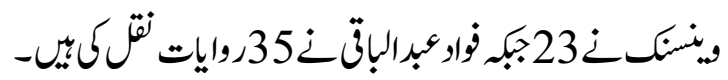

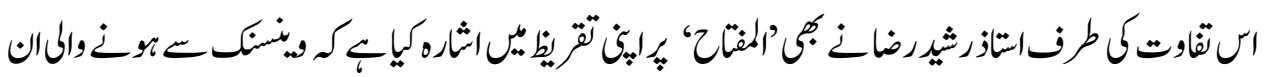

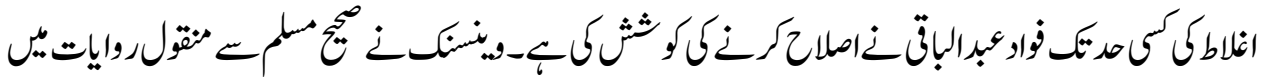

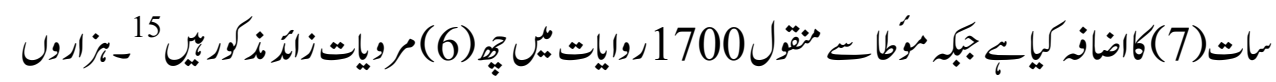

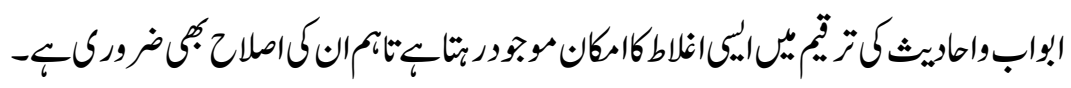

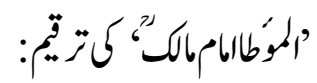

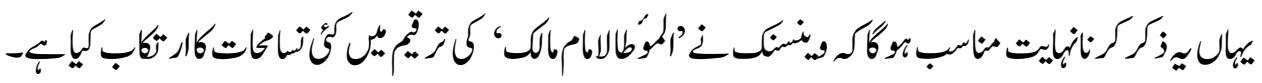

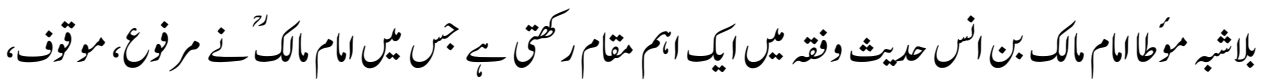

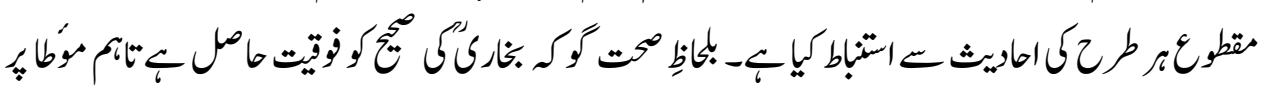

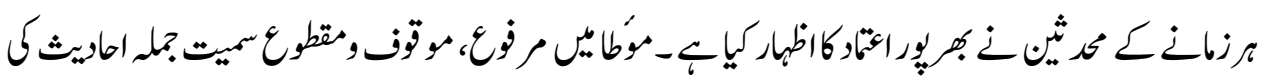

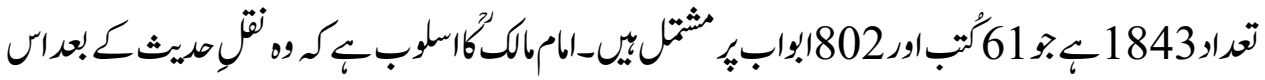

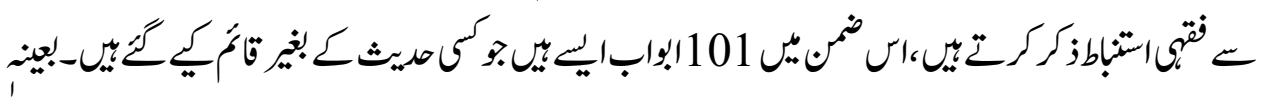

15. Ibid. pp. 36-38 
The Scholar Islamic Academic Research Journal

Vol. 7, No. 2 || July-December 2021 || P. 1-17

https://doi.org/10.29370/siarj/issue13urduar1

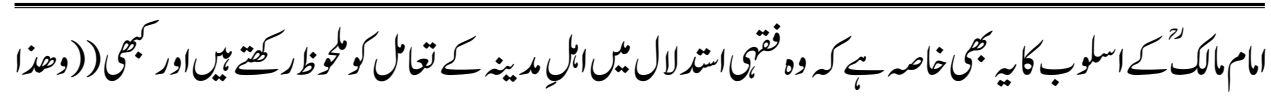

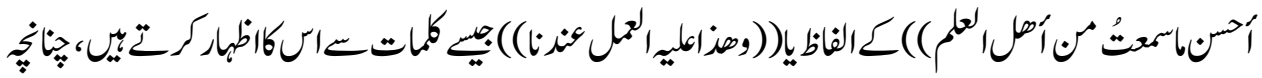

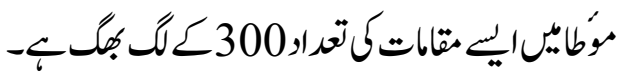

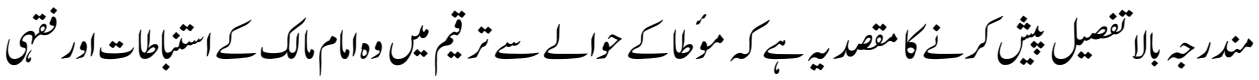

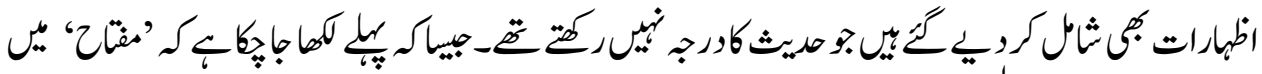

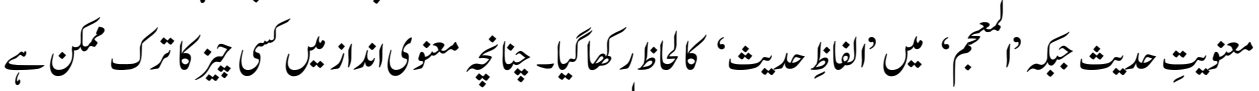

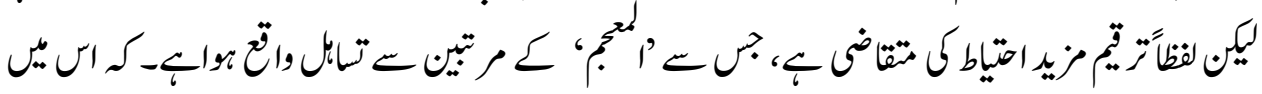

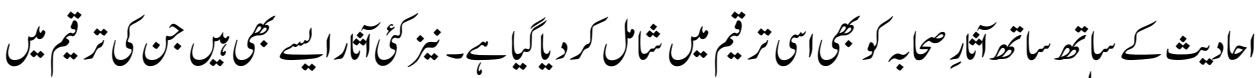

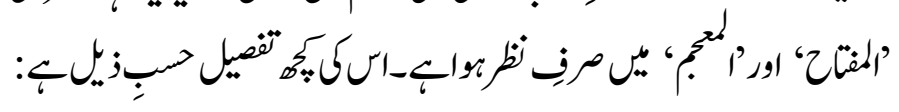

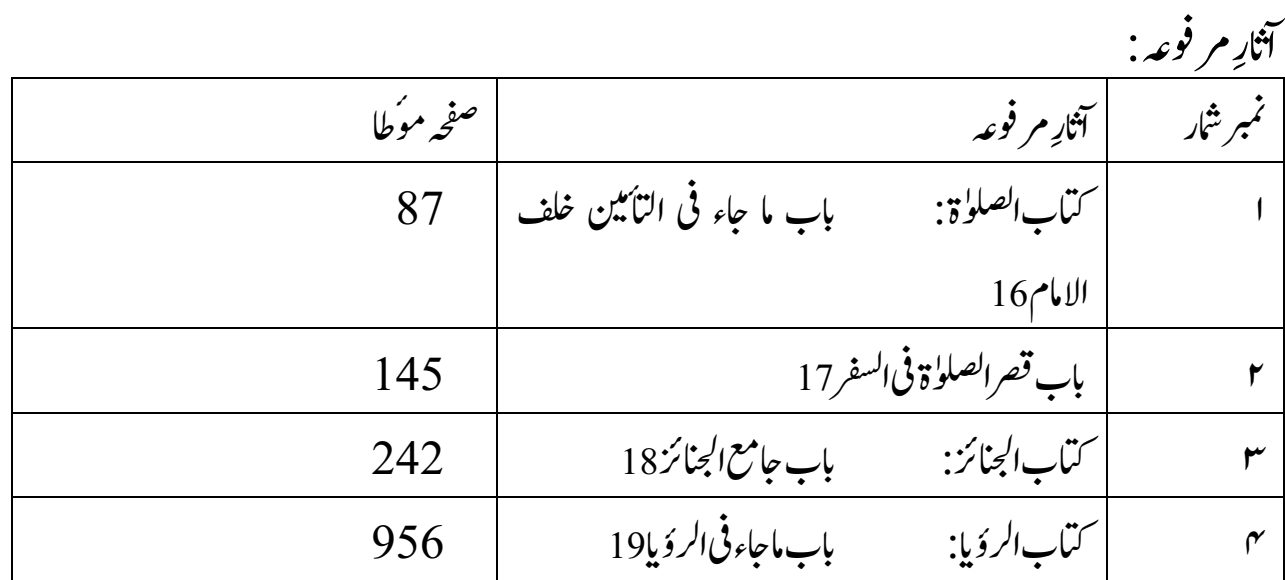

آثنارِمو قوفِ

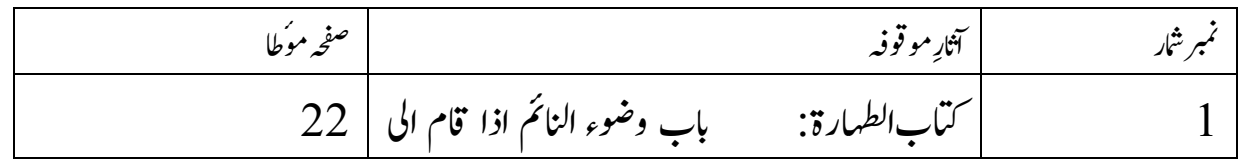

16. Al-Mujam, 1/107

17 Al-Mujam, 1/364

18. Al-Mujam, 6/84

19. It is not mentioned in Al-Mujam 
The Scholar Islamic Academic Research Journal

Vol. 7, No. 2 || July-December 2021 || P. 1-17

https://doi.org/10.29370/siarj/issue13urduar1

\begin{tabular}{|c|c|c|}
\hline & الصلوات20 & \\
\hline 26 & 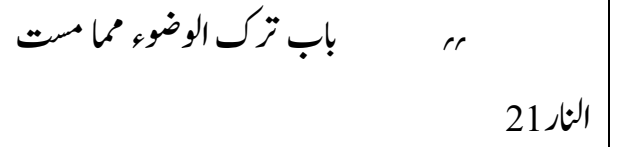 & 2 \\
\hline 77 & باب|فتحاح/صلواة22 & 3 \\
\hline 96 & بابتامتامامصلمازكرازاثك & 4 \\
\hline 116 & اصلاةفقر مثنان24 & 5 \\
\hline \multicolumn{3}{|r|}{ 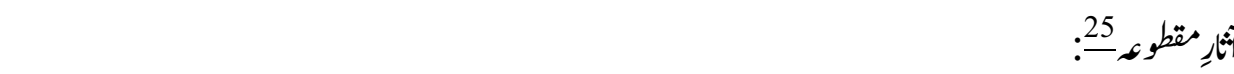 } \\
\hline صنح مُوطا & آثَاِِموقوفْ & نمبر \\
\hline 21 & 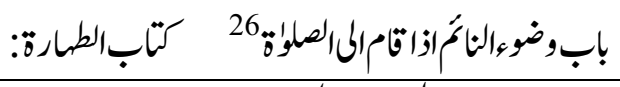 & .1 \\
\hline 38 & 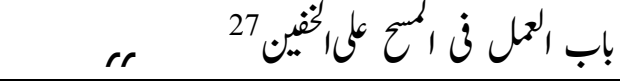 & .2 \\
\hline 72 & 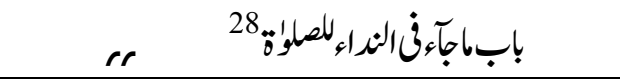 & .3 \\
\hline 529 & باب خآءالسور 29 كتاب لنكاح: & .4 \\
\hline 582 & باب جاتعدة:الطاق 30 كتاب الطاق: & .5 \\
\hline
\end{tabular}

20. Al-Mujam, 7/470

21. Al-Mujam, 6/208

22. Al-Mujam, 5/47

23. Al-Mujam, 6/441

24. Not mentioned in Al-Mujam.

Note: Mauqoof Asar have been described in Al-Mujam 33 times.

25. Takhreej of Asaar-e-Maqtoa has been described 50 times.

26. Al-Mujam, 7/357

27. Al-Mujam, 7/358

28. Al-Mujam, 6/399

29. Al-Mujam, 3/274

30. Al-Mujam, 4/24 
The Scholar Islamic Academic Research Journal

Vol. 7, No. 2 || July-December 2021 || P. 1-17

https://doi.org/10.29370/siarj/issue13urduar1

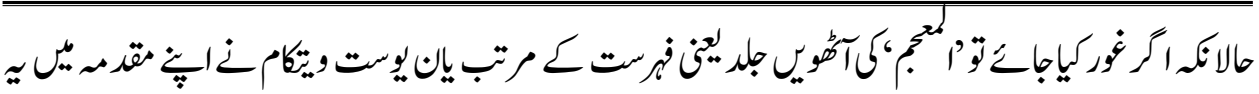

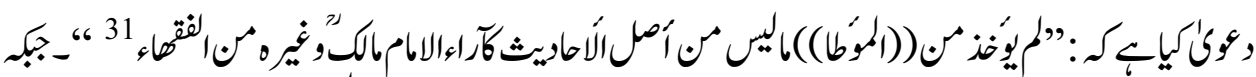

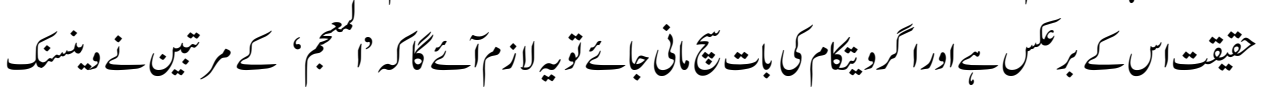

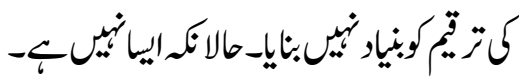

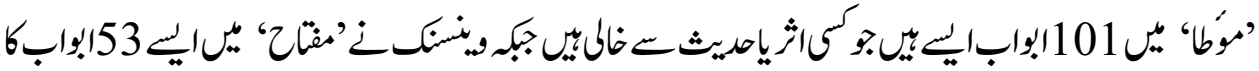

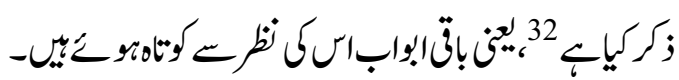

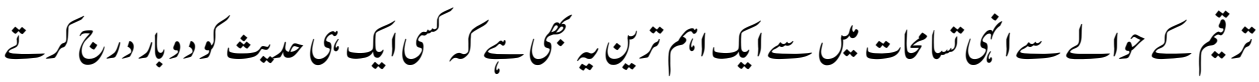

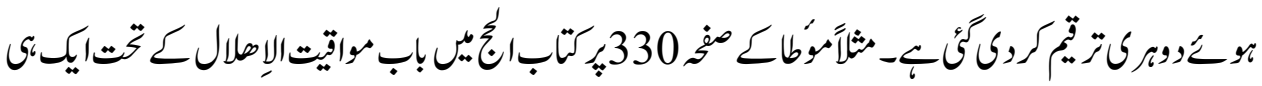

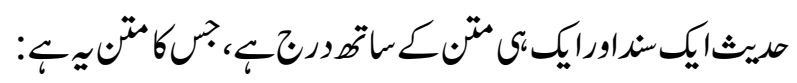

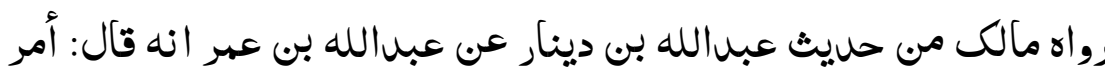

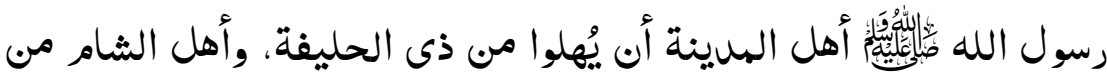
الجُحفة وأهل نجل من قرث-

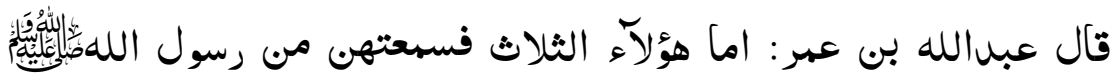

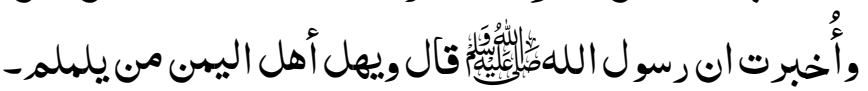

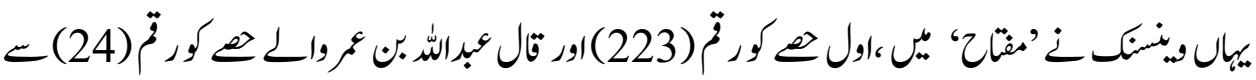

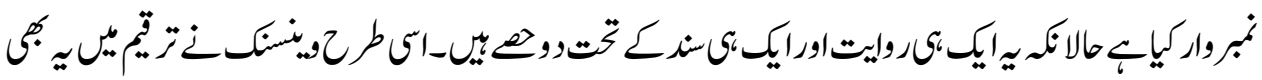

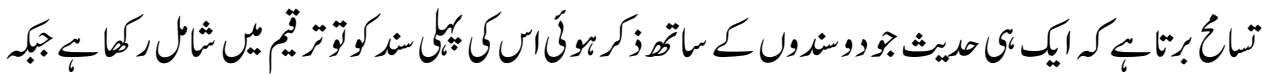

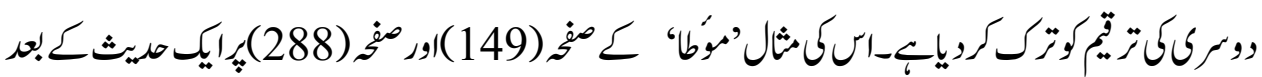

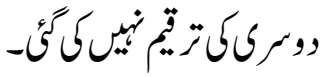

31. Al-Mujam, 7/k

32. Hayyani, Muhammad Abdullah. Mimma Yulahiz ala kitabai Miftah Kunuz al Sunnah wal Mujama al Mufahris li alfaz al Hadith. pp. 58-66 


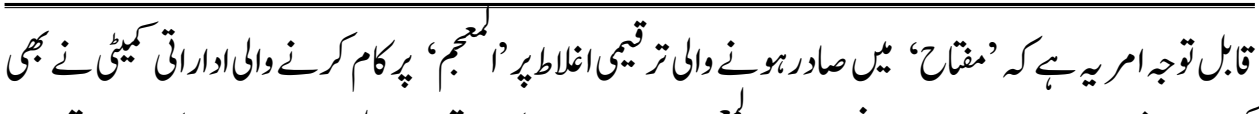

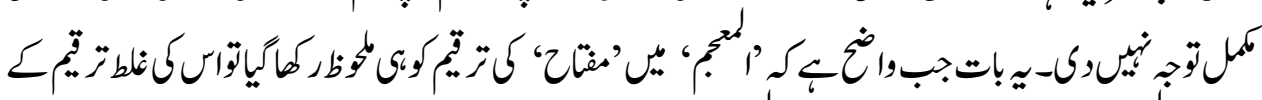

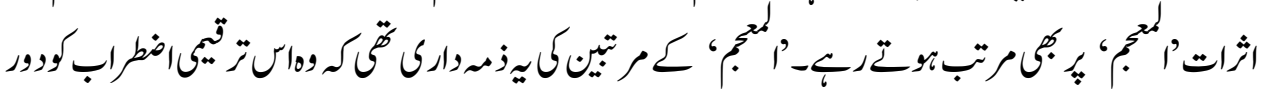

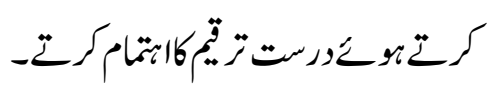

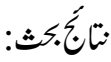

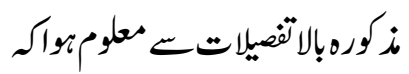

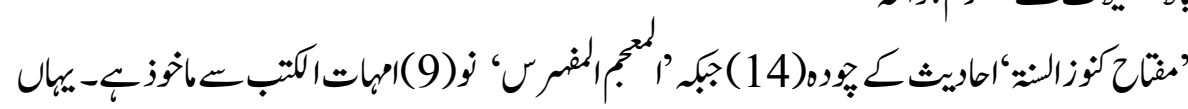

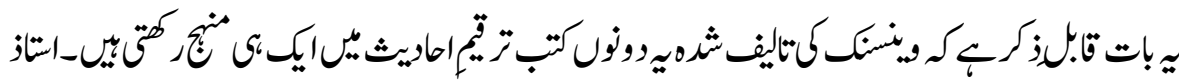

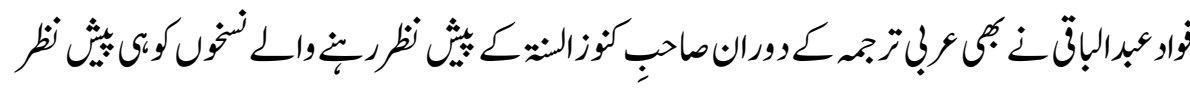

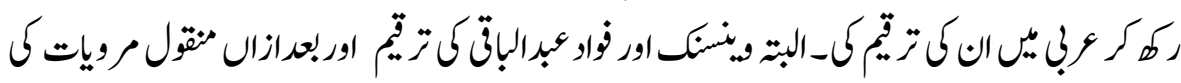

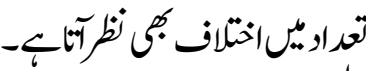

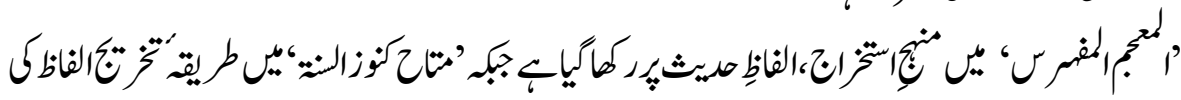

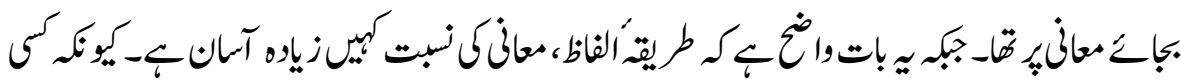

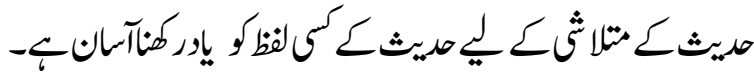

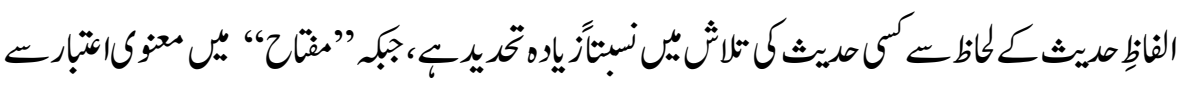

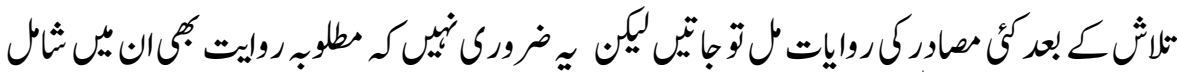

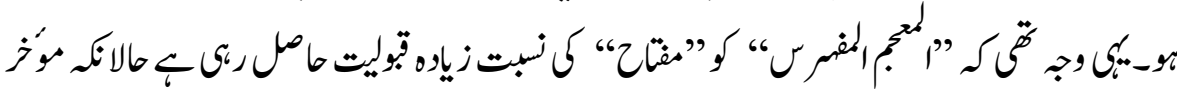

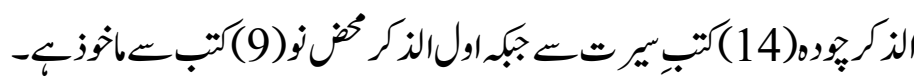

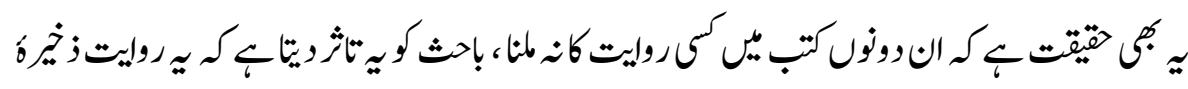

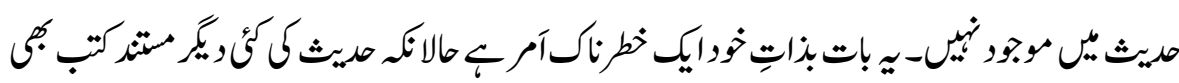

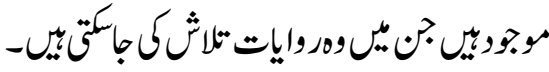

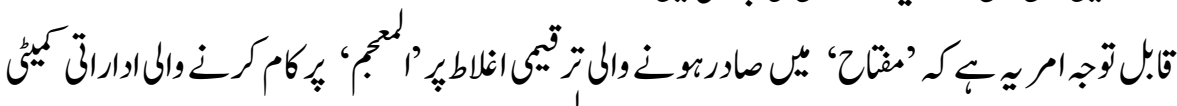

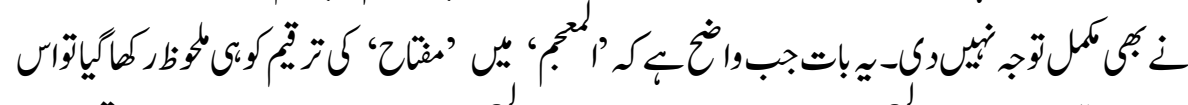

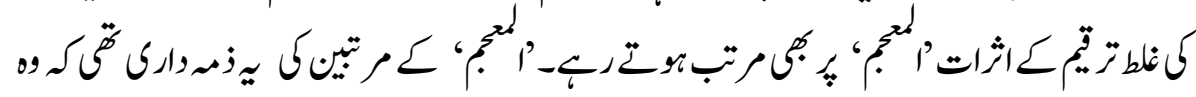


The Scholar Islamic Academic Research Journal

Vol. 7, No. 2 || July-December 2021 || P. 1-17

https://doi.org/10.29370/siarj/issue13urduar1

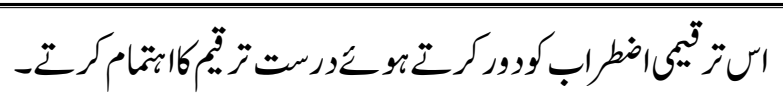

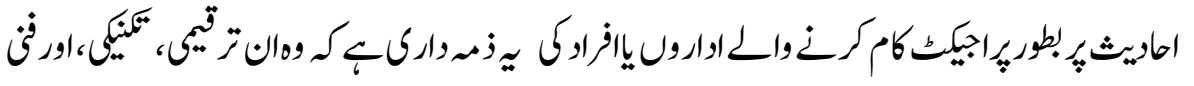

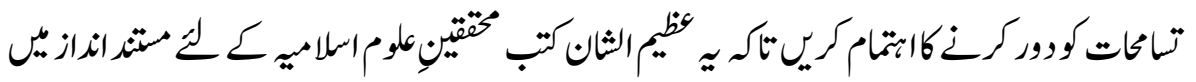

$$
\begin{aligned}
& \text { قا. }
\end{aligned}
$$

